\title{
The therapeutic approaches in children and adolescent with Tourette's disorder
}

\author{
Yoo-Sook Joung ${ }^{1}$, Moon-Soo Lee ${ }^{2}$ \\ ${ }^{1}$ Department of Psychiatry, Samsung Medical Center, Sungkyunkwan University School of Medicine, Seoul, Korea \\ ${ }^{2}$ Division of Child and Adolescent Psychiatry, Department of Psychiatry, Korea University Guro Hospital, Korea University College \\ of Medicine, Seoul, Korea
}

Received: November 27, 2020

Revised: December 29, 2020

Accepted: December 30, 2020

Corresponding author:

Yoo-Sook Joung

Department of Psychiatry,

Samsung Medical Center,

Sungkyunkwan University

School of Medicine, 81 Irwon-ro,

Gangnam-gu, Seoul 06351, Korea

Tel: +82-2-3410-3589

E-mail:yschoung@skku.edu

\section{ABSTRACT}

A tic is a sudden, rapid, recurrent, and nonrhythmic motor movement and vocalization. In Tourette's disorder (TD), the tics may wax and wane in frequency and severity but persist for more than one year since the first tic onset. TD may have a high spontaneous remission rate. However, in some patients, tic symptoms persist even after adulthood. Since tic symptoms develop from a very young age and have wax and wane patterns during the development period, uncontrolled symptoms can cause both subjective distress and functional disability in activities of daily living. Even if psychoeducation and behavioral therapy are considered first, the treatment is determined by considering various factors such as severity of symptoms, subjective distress, physical pain, and functional impairment caused by symptoms. In addition to the antipsychotics that have been used so far, several drugs have recently been tried based on the pathogenesis hypothesis, and the evidence for treatment effects is increasing. This article reviewed possible interventions with proven evidence of TD, including psychopharmacologic treatment.

Keywords: Adolescent; Child; Psychopharmacology; Psychosocial intervention; Tourette syndrome

\section{INTRODUCTION}

Tourette's disorder (TD) is a neurodevelopmental disorder characterized by multiple motor and one or more vocal tics. Both motor and vocal tics are sudden, rapid, recurrent, nonrhythmic movement, and vocalization. The estimated prevalence of TD ranges from 3 to 8 per 1,000 in school-aged children. TD typically has a prepubertal onset (typically between ages 4 and 6 years). Peak severity appears at the age of 10 and 12 years, declining in severity during adolescence [1]. Boys are more commonly affected than girls [2]. Symptoms usually begin with transient bouts of simple motor tics in the face. Over time, tic symptoms spread to the shoulders, extremities, and torso with complexity. Vocal tics appear 2 to 4 years after the onset of motor tics [3]. In most cases, tics fluctuate in their anatomical sites, complexity, intensity, and frequency. The repetitive episodes of fluctuation of tic symptoms often frustrate patients and
This is an Open Access article distributed under the terms of the Creative Commons Attribution Non-Commercial License (https:// creativecommons.org/licenses/ by-nc/4.0/). 
their parents.

Various biochemical, pathological, and imaging studies support the notion that TD is a neurodevelopmental disorder of neurotransmission resulting in the dysfunction of the cortico-striatal-thalamic-cortical (CSTC) circuitry (Fig. 1). It has been hypothesized that the interaction between genetic and environmental factors is responsible for the dysfunction of the CSTC. Recently, the role of the basal ganglia in the pathogenesis of TD has been emphasized. The medium spiny neuron (MSN), which accounts for more than $80 \%$ of all striatum cells, receives an excitatory glutamate signal from the cortex and sends an inhibitory GABAergic signal to the globus pallidus pars interna (GPi) and substantia nigra. GABAergic parvalbumin (PV)-positive fast-spiking interneuron (FSN) projects inhibitory GABAergic innervation to the MSN. Tonically active neurons (TANs) project to the FSN. The innervation from the GPi to the thalamus is inhibitory and regulates the excitation of the thalamus. When these pathways of normal processes are broken, tic symptoms develop or aggravate. Decreased inhibitory control, which is the role of MSN, can contribute to the dysfunction of the CSTC circuit $[4,5]$.

The CSTC circuit contains a substance made of dopamine; however, in addition to dopamine, a variety of other neu-

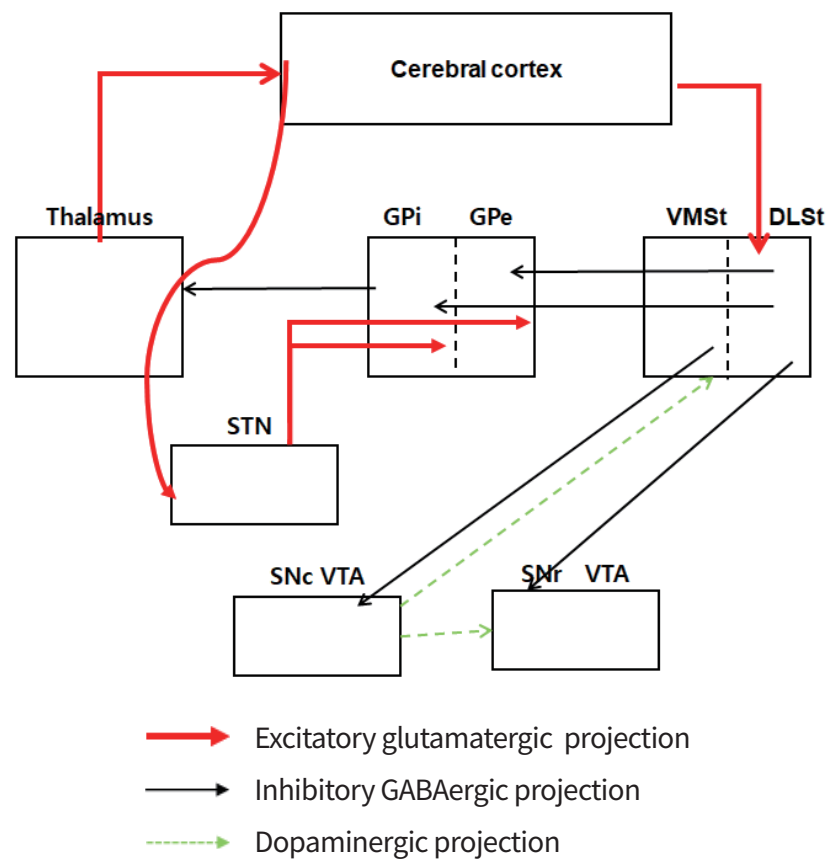

Fig. 1. Schematic diagram of cortico-striatal-thalamic-cortical (CSTC) tract in Tourette's disorder. GPi, internal segment of the globus pallidus; Gpe, external segment of the globus pallidus; STN, subthalamic nucleus; SNc, pars compacta of the substantia nigra; VTA, ventral tegmental area; SNr, pars reticulate of the substantia nigra; VMSt, ventromedial striatum; DLSt, dorsolateral striatum. rotransmitters are involved [6]. The hypotheses for developmental dopamine disorder for TD postulate an excess of nigrostriatal dopaminergic activity, whether through supersensitive dopamine receptors, dopamine hyperinnervation, or abnormal presynaptic terminal function [5]. Various kinds of pharmacological data support the dopamine model. The agents of dopaminergic D2 receptor blockers have been found to be effective in the alleviation of tics [7]. In addition, after administration of tetrabenazine, which inhibits the uptake of dopamine into synaptic vesicles and diminishes the amount of dopamine released at synapses, it has been reported that tic symptoms improved. Noradrenergic mechanisms have come to receive academic attention for their involvement in the pathology of TD, after reports of the clinical effects of a2-adrenergic agonists in patients with TD [8] and the regularization of ventral tegmental area dopamine cell firing by clonidine, an a2-adrenergic agonist, through indirect influence on endogenous monoamines in the brain [9].

The excitatory neurotransmitter glutamate neurons by the corticostriatal, corticosubthalamic, and thalamocortical projections are key players in the functional anatomy of the basal ganglia and the CSTC loops. Research on the neurobiological abnormalities of the CSTC circuits, including glutamate, has been reported [10]. In addition, the effect of the use of glutamate modulators in TD showed glutamate's major role in CSTC circuits [11]. A recent neuropathological study of postmortem TD brains revealed that individuals with TD had a markedly higher total neuron number in the GPi and a lower neuron number and density in the globus pallidus pars externa and in the caudate (Cd) compared with normal controls [12]. A higher number and proportion of GPi neurons were positive for the calcium-binding protein PV in tissue from TD subjects, whereas lower densities of PV-positive interneurons were observed in both the $\mathrm{Cd}$ and putamen of TD subjects [12]. In the striatum, immunocytochemistry for PV selectively stains GABAergic interneurons, and GABAergic interneurons are incorporated in a feed-forward inhibitory circuit of the striatum [13]. This indicates an imbalance in striatal and GPi inhibitory neuron distribution associated with functional alteration of CSTC circuitry as a fundamental mechanism in TD [12]. Although further research is needed, it is evident that the relative balance of activity between glutamatergic projection neurons and GABAergic cells is likely to be a key factor in the emergence of tic behaviors (Fig. 1) [5]. In the CSTC circuit, it is necessary to consider the effects of the cholinergic system. The cholinergic TANs found through the striatum were decreased in TD patients in the associative 
and sensorimotor regions but not in the limbic regions of the striatum in a postmortem study [14]. This study demonstrates that abnormal complex repetitive behaviors can be elicited by specifically inducing a cholinergic interneuronal deficit in sensorimotor areas of the striatum [15]. These results indicate that the cholinergic system is likely to be involved in the coordination of striatal response via interactions with central dopaminergic and GABAergic neurons.

\section{INTERVENTION}

\section{Psychoeducation}

Psychoeducation, involving the patient as well as relevant caregivers, should be provided at the beginning of treatment. Further, individual causal factors and treatment options should be discussed. Indications for treatment are given when tics cause subjective discomfort, sustained social and emotional problems for the patient, and functional interference [16]. Psychoeducation involves providing detailed information regarding the disorder's characteristics, its natural course and prognosis, the evaluation process, and options for treatment. It is also necessary to discuss what position the caregiver and the patient will take to deal with the disease. Information that is often useful to teachers involves recommendations to allow the child to take an exam by oneself or to be permitted to leave the classroom for short periods to reduce the urge, keeping their classmates out of the attention, to release the tics [17]. In many children with TD with mild severity tics because of the high rate of spontaneous remission, psychoeducation about the condition with some supportive counseling may be sufficient. A key focus is on maintaining and strengthening the child's self-confidence and self-esteem. A supportive approach may be helpful for these purposes [18].

\section{Behavioral intervention}

Among the behavioral intervention methods, habit reversal training (HRT) and exposure and response prevention (ERP) have shown that these forms of therapy are efficacious in controlling tics through clinical trials [19]. The primary active components of the HRT are tic awareness and competing-response training. Awareness training involves self-monitoring of current tics (description of the topography and detailed characteristics of their tics), focusing on the premonitory urge or other early signs that a tic is about to appear. Competing-response training is based on the observation that the performance of a tic results in a decrease in the premoni- tory urge. Over time, the reduction in the urge after the completion of the tic reinforces its repetition. Competing-response training involves engagement in a voluntary behavior physically incompatible with the tic, contingent on the premonitory urge or other signs of impending tic occurrence. Habit reversal was directly compared with supportive psychotherapy for TD in a randomized controlled trial. This trial showed that habit reversal was a more effective treatment than supportive psychotherapy [20].

The application of ERP to reduce tics is based on the association of unpleasant premonitory sensations followed by a motor or vocal tic that relieves the sensation [21]. Based on the learning theory, tics can be viewed as conditioned responses to premonitory stimuli. When such stimuli reoccur over time, the power of the associative interaction between the sensations and the resultant tic behavior is strengthened. ERP aims to interrupt the association, thus preventing the occurrence of the tics. By confronting patients for a prolonged period with the sensations (exposure) and resisting the tic (response prevention), the patients might learn to tolerate the unpleasant sensation (habituation). Habituation will reduce the urge or need to give into the tic, resulting in a reduction in tic behavior.

\section{Psychopharmacotherapy}

Pharmacological treatment is recommended when tics result in significant subjective discomfort, such as muscular pain or physical injury, ongoing social problems/emotional problems, or significant functional impairment [22].

\section{Typical antipsychotics}

The study of drug therapy for TD began in the 1960s [23]. However, despite the long history of antipsychotic use, clinical research has been limited. This is because the medication compliance of the patients was poor due to side effects of antipsychotics such as sedation and extrapyramidal symptoms (EPS), and it was difficult to assess the effectiveness of the treatment due to the wax and wane pattern of TD. The study compared pimozide with a placebo in a crossover study of 20 patients for a 6 -week treatment period. The mean dose of pimozide used was $6.9 \mathrm{mg} / \mathrm{day}$. At the endpoint of the pimozide and placebo phase, the mean tic severity, assessed using the Tourette Syndrome Severity Scale, was 1.52 and 4.42, respectively. More patients allocated to pimozide experienced akinesia, akathisia, or postural rigidity. There were no significant differences in cardiovascular parameters between the groups $[24,25]$. In a double-blind trial involving 
10 patients whose tics were controlled after 1 to 3 months of pimozide therapy, the mean time to relapse was significantly shorter for patients on discontinuous treatment (the placebo group) than for those who continued to receive medication (37 days vs. 231 days). Chronic, longer-term treatment with pimozide appears to be more effective in controlling the course of tics than using the drug acutely to treat an exacerbation [26]. Sallee et al. [27] compared pimozide, haloperidol, and a placebo in a crossover study of 22 patients. The patients received a 6-week treatment phase, with a 2-week placebo baseline period and a 2-week washout period between each treatment phase. The mean pimozide and haloperidol dose was 3.4 and $3.5 \mathrm{mg}$, respectively. Tic severity, measured using the Tourette Syndrome Global Scale, was 17.1, 20.7, and 26.8 after the pimozide, haloperidol, and placebo phases, respectively. Pimozide was significantly different from placebo, whereas haloperidol failed to have a significant effect. Haloperidol showed a higher frequency of severe side effects and significantly greater EPS relative to $\mathrm{pi}$ mozide and placebo. Pimozide and haloperidol did not differ from placebo in their effects on electrocardiogram (ECG) parameters. A significant increase in the level of prolactin was observed in both groups with pimozide and haloperidol compared with placebo. With both a parallel-group and crossover study design, Shapiro et al. [28] compared pimozide, haloperidol, and placebo in 57 patients. Initially, all subjects entered a 6-week parallel trial comparing pimozide, haloperidol, and placebo. The mean pimozide and haloperidol dosages were 10.6 and $4.5 \mathrm{mg}$, respectively. The results suggested that both haloperidol and pimozide were more effective than the placebo, but that haloperidol was slightly more effective than pimozide. The frequency of adverse effects was not significantly different between haloperidol and pimozide. There were no clinically significant cardiac effects at a maximum dosage of $0.3 \mathrm{mg} / \mathrm{kg}$ or $20 \mathrm{mg} /$ day for pimozide and $10 \mathrm{mg} /$ day for haloperidol. Although the corrected QT interval was prolonged during pimozide treatment compared with that during haloperidol treatment, the values for both medications were not in an abnormal range. In a double-blind placebo-controlled, crossover study, Ross and Moldofsky [29] compared the therapeutic effects of pimozide, haloperidol, and placebo in nine patients. There were two 12-day treatment periods, with a 6-day placebo washout between periods. The dosage of pimozide and haloperidol was 10 and $-12 \mathrm{mg}$, respectively. Compared with placebo, both pimozide and haloperidol significantly decreased tic frequency in nine patients with TD. Pimozide was associated with significantly fewer complaints of lethargy. Follow-up 4 to 20 months later showed that six of seven patients with pimozide and one of two patients with haloperidol had greater than $75 \%$ improvement in symptoms.

\section{Atypical antipsychotics}

Six randomized controlled trials have assessed risperidone for the treatment of TD [25]. Among the two trials comparing risperidone with placebo, in a randomized, double-blind, placebo-controlled trial of 8 weeks in 34 subjects, 16 participants treated with risperidone experienced a 32\% reduction from baseline in their Yale Global Tic Severity Scale (YGTSS) total tic scores, with a 7\% reduction in 18 placebo patients. Weight increased significantly with risperidone than with placebo (a gain of $2.8 \mathrm{~kg}$ vs. no change) [30]. Dion et al. [31] studied a double-blind, placebo-controlled trial with risperidone of 8 weeks in 48 participants. In the risperidone (median dosage of $2.5 \mathrm{mg} /$ day) and placebo groups, $60.8 \%$ and $26.1 \%$ improved by at least 1 point on the 7-point Global Severity Rating of the Tourette Syndrome Severity Scale, respectively. In the risperidone group, there were significantly higher hypokinesia scores on the Extrapyramidal Symptom Rating Scale and significantly higher rates of fatigue and somnolence than in the placebo group. Two trials made a comparison between risperidone and pimozide. In a randomized, double-blind, crossover trial, Gilbert et al. [32] compared pimozide with risperidone in 19 patients with two 4-week treatment phases, with a 2-week placebo washout between treatments. The mean pimozide and risperidone dosages were 2.4 and $2.5 \mathrm{mg}$, respectively. At the endpoint of the treatment phase with pimozide and risperidone, tic severity measured on the YGTSS was 34.2 and 25.2, respectively. There was no difference between pimozide and risperidone for severe adverse events or changes in ECG parameters, though there was greater weight gain for risperidone than for pimozide. In a double-blind, parallel-group 12-week study [33] comparing pimozide to risperidone, the change in tic severity from baseline to endpoint was significantly improved for both treatment groups, but no significant difference in the effect between risperidone and pimozide groups. There was no significant difference between the two groups for adverse events of EPS. In comparison between risperidone and clonidine of the effect and tolerability for the patients with TD, Gaffney et al. [34] studied in an 8-week trial of 21 children. Children with risperidone and clonidine had significant improvement in the YGTSS-Global Severity scores from baseline to endpoint, but there was no significant dif- 
ference in the level of tic reduction between the groups. In children treated with clonidine and risperidone, the most common adverse effect was sedation. There was no significant difference between groups in EPS and significant changes in ECG parameters. Ghanizadeh and Haghighi [35] compared risperidone and aripiprazole in an 8-week double-blind, randomized clinical trial of 60 children. Significant reductions in tic symptoms from baseline to endpoint in the YGTSS Total Tic Scores were seen in both groups, with no significant difference in the effect. Increased appetite and drowsiness were the most common adverse effects in both groups. In all clinical trials with risperidone, an improvement in tics was reported. Trials comparing risperidone with pimozide, risperidone with aripiprazole, and risperidone with clonidine found similar benefits with each treatment [25].

There are two randomized, double-blind, placebo-controlled trials of aripiprazole for TD. In a 10-week multicenter, double-blind, randomized, placebo-controlled trial [36], 61 children and adolescents were randomly assigned to placebo or aripiprazole. There was a significant difference in the YGTSS Total Tic Score at the endpoint between children with aripiprazole and placebo. A mean difference of 5.35 points suggests that aripiprazole is superior to placebo. There was no difference between the groups in EPS. Although there were no significant or clinically significant changes in blood pressure, heart rate, or ECG, increases in weight, body mass index, and waist circumference were significantly higher in children with aripiprazole. In a randomized, placebo-controlled study, Sallee et al. $[25,37]$ compared low-dose or highdose aripiprazole with placebo in an 8-week trial of 133 children and adolescents. Both low-dose and high-dose aripiprazole were associated with a significant improvement in tics. Sedation was the most common adverse effect in children with aripiprazole. EPS-related adverse events were reported in $2.3 \%$ of the low-dose group, $13.3 \%$ of the highdose group, and in none of the placebo group. Clinically relevant weight gain occurred in $18.2 \%$ of the low-dose group, $9.3 \%$ of the high-dose group, and $9.1 \%$ of the placebo group. Twenty-eight children and adolescents, aged 7 to 17 years, were randomized to ziprasidone or placebo for 8 weeks with a mean dose of $28.2 \mathrm{mg} /$ day to evaluate the effect of ziprasidone on the treatment of TD. The score in the YGTSS Total Tic Score reduced from 27.7 to 16.8 with ziprasidone and from 24.6 to 22.9 with placebo. The most common adverse event associated with ziprasidone was sedation. Scores measuring EPS were similar between the groups. In five children with ziprasidone, prolactin levels increased transiently to above the upper limit of the normal, and one boy developed mild gynecomastia. There were no clinically significant changes in heart rate, blood pressure, or ECG parameters [25,38].

Onofrj et al. [39] compared the clinical effects of olanzapine and pimozide through a 52-week double-blind crossover control study in patients with TD. Doses of 10 and $5 \mathrm{mg} /$ day of olanzapine had significant clinical effects compared to 4 and $2 \mathrm{mg} /$ day of pimozide. Other open-label studies have shown an improvement in tic symptoms [40-42]. The dosage of olanzapine was 10 to $15 \mathrm{mg} /$ day. Patients with olanzapine have shown sedation, weight gain, and an increase in appetite.

In an open-label study of quetiapine, a significant decrease in tic symptoms after the 8-week period was reported [43]. The most frequent side effects were sedation and weight gain.

Although the specific D2 antagonists, tiapride and sulpiride in the class of benzamides, have little to no antipsychotic effects. In a double-blind, randomized, placebo-controlled, crossover study for tiapride [44], the effect of tic suppression was reported in patients with tiapride. There was no adverse effect on cognitive performance or neurosecretory regulation, except for hyperprolactinemia. In an open-label study with 189 children with TD, after a 6-week period, the children treated with sulpiride showed improved tic symptoms. Side effects included sedation [45].

\section{a2-Adrenergic agonist}

Several trials have provided evidence for the efficacy of $a$ 2-adrenergic drugs, clonidine, and guanfacine to alleviate tics in patients with TD, although Goetz's study [46] that compared clonidine with placebo in a double-blinded, crossover design for 6 months did not find differences between clonidine and placebo in motor or vocal tic number or severity of 30 children and adults with TD. In a previous study [47] comparing clonidine, desipramine, and placebo in an 18week crossover study of 34 children with TD and attention deficit hyperactivity disorder (ADHD), children with desipramine showed significant improvement compared to those with placebo, while clonidine did not have a significant effect. In double-blind, randomized placebo-controlled studies, Leckman et al. [48] reported that clonidine treatment resulted in a significant reduction in motor tics but not in vocal tics when compared with placebo. The study in a 16-week trial of 136 children for both TD/chronic tic disorder and ADHD by The Tourette Syndrome Study Group found a significant improvement of tics in three active treatment groups 
(clonidine, methylphenidate, and combined clonidine and methylphenidate) in comparison with placebo [49]. In addition to the effects of oral medications, clonidine adhesive patches showed significantly more effects than placebo in treating tics [50]. Among three randomized controlled trials of guanfacine compared with placebo for the treatment of tics in children and adolescents, one study reported a significant improvement of tics in the guanfacine treatment group [51]. In two other studies [52,53], guanfacine did not significantly reduce the tic symptoms compared to placebo.

\section{Vesicular monoamine transporter type 2 inhibitors}

Tetrabenazine, which depletes presynaptic dopamine and serotonin stores and blocks postsynaptic dopamine receptors, has been reported to reduce tics. Results of a retrospective chart review of 77 patients with TD showed that treatment for 2 years with tetrabenazine resulted in an improvement in tic symptoms in over $80 \%$ of patients, suggesting long-term benefits of tetrabenazine [54]. In a long-term, open-label study by Jankovic et al. [55], four out of nine patients with TD had marked improvement in tic symptoms, and three had mild improvement. In a 6-week, open-label trial [56] with deutetrabenazine in patients with TD, there was a decrease in tic symptoms. Side effects included fatigue, headache, and irritability.

\section{GABA receptor agonist}

Baclofen is a GABA receptor agonist. In an open-label trial, it was suggested that baclofen could be effective in treating tic symptoms of TD. Two hundred and sixty-four patients were treated with baclofen (10 to $80 \mathrm{mg} /$ day) for 4 weeks. The starting dose was $10 \mathrm{mg} /$ day for all patients and the drug dose increased by $10 \mathrm{mg} /$ week until symptoms of tics were sufficiently improved or side effects occurred [57]. About $96 \%$ of patients showed a significant improvement in tic symptoms in 2 weeks. The frequent side effects were sedation and drowsiness. In a double-blind, randomized placebo-controlled study [58], 10 children, aged 8 to 14 years with TD were treated with baclofen ( $20 \mathrm{mg}$ three times daily) and placebo for 4 weeks. The improvement of tic symptoms in the YGTSS was not significant, although there was a significant reduction in the impairment score. Prominent side effects were not reported.

Topiramate is a broad-spectrum anticonvulsant that is GABAergic and blocks alpha-amino-3-hydroxy-5-methyl-4isoxazole-propionic acid/kainate subtypes of glutamate receptors [59]. In one double-blind, randomized placebo-con- trolled trial [60], topiramate was superior to placebo in reducing the tic symptoms measured by the YGTSS Total Tic Score in 29 patients with TD and moderate to severe symptoms. During 10 weeks of active treatment period, the mean dose of topiramate was $118 \mathrm{mg} /$ day (range, 50 to 200). Although the significance was not clearly stated in the study, a mean weight loss of $2.1 \mathrm{~kg}$ in the topiramate treatment group was shown compared to the weight gain of $1.9 \mathrm{~kg}$ in the placebo group.

\section{Botulinum toxin $A$}

Botulinum toxin (BTX) is a neurotoxic protein that inhibits acetylcholine release at the neuromuscular junction [59] and may be an effective treatment modality for various medical conditions with abnormal muscle contractions. In an openlabel trial [61] to evaluate the effect of BTX in reducing tic symptoms, 35 patients were treated with BTX at anatomical sites with the most severe tic symptoms. BTX was effective in reducing motor tics and premonitory urge. Side effects included neck weakness, dysphagia, ptosis, nausea, hypophonia, fatigue, and generalized weakness, all of them mild and of transient severities. In one double-blind, randomized placebo-controlled study for BTX, 20 patients with simple motor tics received BTX and placebo. After 2 weeks, BTX had a significant effect on the decrease in tic symptoms and premonitory urge when compared with placebo, even if the patients treated with BTX did not report the therapeutic effect subjectively [62].

\section{Complementary and alternative agents}

Omega-3 fatty acids (O3FAs) are long-chain polyunsaturated fatty acids with two main forms of docosahexaenoic acid and eicosapentaenoic acid [59]. The efficacy of O3FA in children and adolescents with TD was examined through a double-blind, randomized placebo-controlled design in thirty-three children and adolescents (ages 6 to 18) for 20 weeks. At the endpoint, patients with O3FA tic symptoms were not significantly improved compared to those with placebo in response rates and mean scores on the YGTSS-Tic (53\% vs. $38 \%$ and 15.6 vs. 17.1, respectively). Nevertheless, patients on O3FA in comparison with patients taking placebo showed a tendency to be lower on mean YGTSS-Global scores (31.7 vs. 40.9). O3FA is not effective in reducing tic symptoms, and it might be helpful to alleviate tic-related impairment [63].

$\mathrm{N}$-acetylcysteine (NAC) is a naturally occurring, safe, and inexpensive amino acid supplement that has been demonstrated to modulate glutamate. NAC is converted to cystine, 


\section{PRECISION AND FUTURE MIEDICINE}

Yoo-Sook Joung, et al.

a substrate for the glutamate/cystine antiporter located on glial cells. The uptake of cystine by glia causes glial release of glutamate into the extrasynaptic space, reducing the synaptic release of glutamate [64]. Bloch et al. [65] examined the efficacy of NAC in reducing tic symptoms in 31 children and adolescents (8 to 17 years of age) with TD in a double-blind, placebo-controlled, add-on trial for 12 weeks. The initial dose of NAC was $600 \mathrm{mg}$ twice a day for 1 to 2 weeks and increased by 1,200 mg twice a day for the remainder of the 12week period. There was no significant difference between NAC and placebo in reducing tic severity.

\section{Deep brain stimulation}

Deep brain stimulation (DBS) has been attempted in patients with TD who have severe tic symptom-related disabling problems and a medication-refractory state. The results of double-blind or open trials of active stimulation on the globus pallidus and thalamus demonstrated a reduction of tic symptoms [66-70]. However, as the target group was adults and severe side effects such as infection, stroke, motor symptoms, worsening tic symptoms, or DBS-induced hypomania were reported during implementation, it is not clear whether this intervention will benefit children and adolescents.

\section{CONCLUSION}

The medications for TD that have been approved by the Food and Drug Administration (FDA) are the typical antipsychotic agents haloperidol and pimozide, which block D2 dopamine receptors, and the atypical antipsychotic agent aripiprazole, which is a D2 receptor antagonist and 5HT2 receptor partial agonist. In particular, aripiprazole is meaningful because it is the first FDA-approved drug of TD among atypical antipsychotics. Since the FDA approval of haloperidol for $T D$, many clinical trials have proved the effectiveness of the tic suppression of antipsychotics. Despite strong evidence of the effect of TD, less therapeutic effects, and side effect profiles in some patients with TD have led to attempts to find alternatives other than antipsychotics. There are studies of the significant effects of tic suppression of various kinds of drugs, but they have not yet been approved by the FDA. Therefore, medication for TD is often prescribed "off-label." Since the treatment was proven effective in different kinds of drugs other than antipsychotics, based on efficacies for reduction of tic symptoms and side effect profiles, the Canadian guidelines suggest that clonidine and guanfacine should be considered as first-line therapies for tics if it is deemed necessary to use a drug to treat tic symptoms. Second-line therapies include risperidone and aripiprazole. Pimozide, haloperidol, and ziprasidone may be considered in the following thirdline therapies [71]. No matter which line of medication clinicians are using, they should inform the patient and caregiver at the beginning of the drug administration that medication is intended to reduce tic symptoms, not to change the natural course over a long disease period. Moreover, because the wax and wane pattern is one of the natural processes of TD and the tic symptoms fluctuate regardless of drug administration, it should be considered that when symptoms worsen, this may be caused by the 'wax' period and further dosage increases should be made carefully.

\section{CONFLICTS OF INTEREST}

No potential conflict of interest relevant to this article was reported.

\section{ORCID}

Yoo-Sook Joung https://orcid.org/0000-0002-9225-4643

Moon-Soo Lee https://orcid.org/0000-0003-0729-6943

\section{AUTHOR CONTRIBUTIONS}

Conception or design: YSJ.

Acquisition, analysis, or interpretation of data: YSJ, MSL.

Drafting the work or revising: YSJ, MSL.

Final approval of the manuscript:YSJ.

\section{REFERENCES}

1. American Psychiatric Association. Diagnostic and statistical manual of mental disorders: DSM-5. 5th ed. Arlington (VA): American Psychiatric Association; 2013.

2. Freeman RD; Tourette Syndrome International Database Consortium. Tic disorders and ADHD: answers from a world-wide clinical dataset on Tourette syndrome. Eur Child Adolesc Psychiatry 2007;16 Suppl 1:15-23.

3. Leckman JF, Zhang H, Vitale A, Lahnin F, Lynch K, Bondi C, et al. Course of tic severity in Tourette syndrome: the first two decades. Pediatrics 1998;102:14-9.

4. Leckman JF, Vaccarino FM, Kalanithi PS, Rothenberger A. Annotation: Tourette syndrome: a relentless drumbeat: driven by misguided brain oscillations. J Child Psychol Psychiatry 2006;47:537-50. 
PRECISION AND FUTURE MIEDICINE

The therapeutic approaches of Tourette's disorder

5. Leckman JF, Bloch MH, Smith ME, Larabi D, Hampson M. Neurobiological substrates of Tourette's disorder. J Child Adolesc Psychopharmacol 2010;20:237-47.

6. Singer HS, Minzer K. Neurobiology of Tourette's syndrome: concepts of neuroanatomic localization and neurochemical abnormalities. Brain Dev 2003;25 Suppl 1:S7084.

7. Scahill L, Erenberg G, Berlin CM Jr, Budman C, Coffey BJ, Jankovic J, et al. Contemporary assessment and pharmacotherapy of Tourette syndrome. NeuroRx 2006;3:192-206.

8. Cohen DJ, Young JG, Nathanson JA, Shaywitz BA. Clonidine in Tourette's syndrome. Lancet 1979;2:551-3.

9. Grenhoff J, Svensson TH. Clonidine modulates dopamine cell firing in rat ventral tegmental area. Eur J Pharmacol 1989;165:11-8.

10. DeVito TJ, Drost DJ, Pavlosky W, Neufeld RW, Rajakumar N, McKinlay BD, et al. Brain magnetic resonance spectroscopy in Tourette's disorder. J Am Acad Child Adolesc Psychiatry 2005;44:1301-8.

11. Singer HS, Morris C, Grados M. Glutamatergic modulatory therapy for Tourette syndrome. Med Hypotheses 2010; 74:862-7.

12. Kalanithi PS, Zheng W, Kataoka Y, DiFiglia M, Grantz H, Saper CB, et al. Altered parvalbumin-positive neuron distribution in basal ganglia of individuals with Tourette syndrome. Proc Natl Acad Sci U S A 2005;102:13307-12.

13. Kita H, Kosaka T, Heizmann CW. Parvalbumin-immunoreactive neurons in the rat neostriatum: a light and electron microscopic study. Brain Res 1990;536:1-15.

14. Kataoka Y, Kalanithi PS, Grantz H, Schwartz ML, Saper C, Leckman JF, et al. Decreased number of parvalbumin and cholinergic interneurons in the striatum of individuals with Tourette syndrome. J Comp Neurol 2010;518:277-91.

15. Ganos C, Hartmann A. Altered cholinergic neurotransmission in Tourette syndrome. Mov Disord 2015;30:638.

16. Roessner V, Plessen KJ, Rothenberger A, Ludolph AG, Rizzo R, Skov L, et al. European clinical guidelines for Tourette syndrome and other tic disorders. Part II: pharmacological treatment. Eur Child Adolesc Psychiatry 2011; 20:173-96.

17. Rey JM, Martin A. JM Rey's IACAPAP e-textbook of child and adolescent mental health. Geneva (CH): International Association for Child and Adolescent Psychiatry and Allied Professions; 2019.

18. Kurlan R. Clinical practice. Tourette's syndrome. N Engl J Med 2010;363:2332-8.

19. Piacentini J, Woods DW, Scahill L, Wilhelm S, Peterson AL,
Chang S, et al. Behavior therapy for children with Tourette disorder: a randomized controlled trial. JAMA 2010;303: 1929-37.

20. Deckersbach T, Rauch S, Buhlmann U, Wilhelm S. Habit reversal versus supportive psychotherapy in Tourette's disorder: a randomized controlled trial and predictors of treatment response. Behav Res Ther 2006;44:1079-90.

21. Leckman JF, Walker DE, Cohen DJ. Premonitory urges in Tourette's syndrome. Am J Psychiatry 1993;150:98-102.

22. Roessner V, Rothenberger A, Rickards H, Hoekstra PJ. European clinical guidelines for Tourette syndrome and other tic disorders. Eur Child Adolesc Psychiatry 2011; 20:153-4.

23. Shapiro AK, Shapiro E. Treatment of Gilles de la Tourette's syndrome with haloperidol. Br J Psychiatry 1968;114:34550.

24. Shapiro AK, Shapiro E. Controlled study of pimozide vs. placebo in Tourette's syndrome. J Am Acad Child Psychiatry 1984;23:161-73.

25. Pringsheim T, Okun MS, Muller-Vahl K, Martino D, Jankovic J, Cavanna AE, et al. Practice guideline recommendations summary: treatment of tics in people with Tourette syndrome and chronic tic disorders. Neurology 2019;92: 896-906.

26. Short-term versus longer term pimozide therapy in Tourette's syndrome: a preliminary study. Neurology 1999;52: 874-7.

27. Sallee FR, Nesbitt L, Jackson C, Sine L, Sethuraman G. Relative efficacy of haloperidol and pimozide in children and adolescents with Tourette's disorder. Am J Psychiatry 1997;154:1057-62.

28. Shapiro E, Shapiro AK, Fulop G, Hubbard M, Mandeli J, Nordlie J, et al. Controlled study of haloperidol, pimozide and placebo for the treatment of Gilles de la Tourette's syndrome. Arch Gen Psychiatry 1989;46:722-30.

29. Ross MS, Moldofsky H. A comparison of pimozide and haloperidol in the treatment of Gilles de la Tourette's syndrome. Am J Psychiatry 1978;135:585-7.

30. Scahill L, Leckman JF, Schultz RT, Katsovich L, Peterson BS. A placebo-controlled trial of risperidone in Tourette syndrome. Neurology 2003;60:1130-5.

31. Dion Y, Annable L, Sandor P, Chouinard G. Risperidone in the treatment of Tourette syndrome: a double-blind, placebo-controlled trial. J Clin Psychopharmacol 2002;22: 31-9.

32. Gilbert DL, Batterson JR, Sethuraman G, Sallee FR. Tic reduction with risperidone versus pimozide in a random- 
ized, double-blind, crossover trial. J Am Acad Child Adolesc Psychiatry 2004;43:206-14.

33. Bruggeman R, van der Linden C, Buitelaar JK, Gericke GS, Hawkridge SM, Temlett JA. Risperidone versus pimozide in Tourette's disorder: a comparative double-blind parallel-group study. J Clin Psychiatry 2001;62:50-6.

34. Gaffney GR, Perry PJ, Lund BC, Bever-Stille KA, Arndt S, Kuperman $S$. Risperidone versus clonidine in the treatment of children and adolescents with Tourette's syndrome. J Am Acad Child Adolesc Psychiatry 2002;41:3306.

35. Ghanizadeh A, Haghighi A. Aripiprazole versus risperidone for treating children and adolescents with tic disorder: a randomized double blind clinical trial. Child Psychiatry Hum Dev 2014;45:596-603.

36. Yoo HK, Joung YS, Lee JS, Song DH, Lee YS, Kim JW, et al. A multicenter, randomized, double-blind, placebo-controlled study of aripiprazole in children and adolescents with Tourette's disorder. J Clin Psychiatry 2013;74:e77280.

37. Sallee F, Kohegyi E, Zhao J, McQuade R, Cox K, Sanchez R, et al. Randomized, double-blind, placebo-controlled trial demonstrates the efficacy and safety of oral aripiprazole for the treatment of Tourette's disorder in children and adolescents. J Child Adolesc Psychopharmacol 2017;27: 771-81.

38. Sallee FR, Kurlan R, Goetz CG, Singer H, Scahill L, Law G, et al. Ziprasidone treatment of children and adolescents with Tourette's syndrome: a pilot study. J Am Acad Child Adolesc Psychiatry 2000;39:292-9.

39. Onofrj M, Paci C, D’Andreamatteo G, Toma L. Olanzapine in severe Gilles de la Tourette syndrome: a 52-week double-blind cross-over study vs. low-dose pimozide. J Neurol 2000;247:443-6.

40. Budman CL, Gayer A, Lesser M, Shi Q, Bruun RD. An open-label study of the treatment efficacy of olanzapine for Tourette's disorder. J Clin Psychiatry 2001;62:290-4.

41. McCracken JT, Suddath R, Chang S, Thakur S, Piacentini J. Effectiveness and tolerability of open label olanzapine in children and adolescents with Tourette syndrome. J Child Adolesc Psychopharmacol 2008;18:501-8.

42. Stamenkovic M, Schindler SD, Aschauer HN, De Zwaan M, Willinger $\mathrm{U}$, Resinger $\mathrm{E}$, et al. Effective open-label treatment of Tourette's disorder with olanzapine. Int Clin Psychopharmacol 2000;15:23-8.

43. Mukaddes NM, Abali O. Quetiapine treatment of children and adolescents with Tourette's disorder. J Child Adolesc
Psychopharmacol 2003;13:295-9.

44. Eggers C, Rothenberger A, Berghaus U. Clinical and neurobiological findings in children suffering from tic disease following treatment with tiapride. Eur Arch Psychiatry Neurol Sci 1988;237:223-9.

45. Ho CS, Chen HJ, Chiu NC, Shen EY, Lue HC. Short-term sulpiride treatment of children and adolescents with Tourette syndrome or chronic tic disorder. J Formos Med Assoc 2009;108:788-93.

46. Goetz CG, Tanner CM, Wilson RS, Carroll VS, Como PG, Shannon KM. Clonidine and Gilles de la Tourette's syndrome: double-blind study using objective rating methods. Ann Neurol 1987;21:307-10.

47. Singer HS, Brown J, Quaskey S, Rosenberg LA, Mellits ED, Denckla MB. The treatment of attention-deficit hyperactivity disorder in Tourette's syndrome: a double-blind placebo-controlled study with clonidine and desipramine. Pediatrics 1995;95:74-81.

48. Leckman JF, Hardin MT, Riddle MA, Stevenson J, Ort SI, Cohen DJ. Clonidine treatment of Gilles de la Tourette's syndrome. Arch Gen Psychiatry 1991;48:324-8.

49. Tourette's Syndrome Study Group. Treatment of ADHD in children with tics: a randomized controlled trial. Neurology 2002;58:527-36.

50. Du YS, Li HF, Vance A, Zhong YQ, Jiao FY, Wang HM, et al. Randomized double-blind multicentre placebo-controlled clinical trial of the clonidine adhesive patch for the treatment of tic disorders. Aust N Z J Psychiatry 2008; 42:807-13.

51. Scahill L, Chappell PB, Kim YS, Schultz RT, Katsovich L, Shepherd E, et al. A placebo-controlled study of guanfacine in the treatment of children with tic disorders and attention deficit hyperactivity disorder. Am J Psychiatry 2001;158:1067-74.

52. Cummings DD, Singer HS, Krieger M, Miller TL, Mahone EM. Neuropsychiatric effects of guanfacine in children with mild Tourette syndrome: a pilot study. Clin Neuropharmacol 2002;25:325-32.

53. Murphy TK, Fernandez TV, Coffey BJ, Rahman O, Gavaletz A, Hanks CE, et al. Extended-release guanfacine does not show a large effect on tic severity in children with chronic tic disorders. J Child Adolesc Psychopharmacol 2017;27: 762-70.

54. Kenney CJ, Hunter CB, Mejia NI, Jankovic J. Tetrabenazine in the treatment of Tourette syndrome. J Pediatr Neurol 2007;5:9-13.

55. Jankovic J, Glaze DG, Frost JD Jr. Effect of tetrabenazine 
on tics and sleep of Gilles de la Tourette's syndrome. Neurology 1984;34:688-92.

56. Jankovic J, Jimenez-Shahed J, Budman C, Coffey B, Murphy T, Shprecher D, et al. Deutetrabenazine in tics associated with Tourette syndrome. Tremor Other Hyperkinet $\operatorname{Mov}$ (N Y) 2016;6:422.

57. Awaad Y. Tics in Tourette syndrome: new treatment options. J Child Neurol 1999;14:316-9.

58. Singer HS, Wendlandt J, Krieger M, Giuliano J. Baclofen treatment in Tourette syndrome: a double-blind, placebo-controlled, crossover trial. Neurology 2001;56:599-604.

59. Quezada J, Coffman KA. Current approaches and new developments in the pharmacological management of Tourette syndrome. CNS Drugs 2018;32:33-45.

60. Jankovic J, Jimenez-Shahed J, Brown LW. A randomised, double-blind, placebo-controlled study of topiramate in the treatment of Tourette syndrome. J Neurol Neurosurg Psychiatry 2010;81:70-3.

61. Kwak CH, Hanna PA, Jankovic J. Botulinum toxin in the treatment of tics. Arch Neurol 2000;57:1190-3.

62. Marras C, Andrews D, Sime E, Lang AE. Botulinum toxin for simple motor tics: a randomized, double-blind, controlled clinical trial. Neurology 2001;56:605-10.

63. Gabbay V, Babb JS, Klein RG, Panzer AM, Katz Y, Alonso CM, et al. A double-blind, placebo-controlled trial of $\omega-3$ fatty acids in Tourette's disorder. Pediatrics 2012;129:e1493-500.

64. Moran MM, McFarland K, Melendez RI, Kalivas PW, Seamans JK. Cystine/glutamate exchange regulates metabotropic glutamate receptor presynaptic inhibition of excitatory transmission and vulnerability to cocaine seeking. J Neurosci 2005;25:6389-93.
65. Bloch MH, Panza KE, Yaffa A, Alvarenga PG, Jakubovski E, Mulqueen JM, et al. $\mathrm{N}$-acetylcysteine in the treatment of pediatric Tourette syndrome: randomized, double-blind, placebo-controlled add-on trial. J Child Adolesc Psychopharmacol 2016;26:327-34.

66. Kefalopoulou Z, Zrinzo L, Jahanshahi M, Candelario J, Milabo C, Beigi M, et al. Bilateral globus pallidus stimulation for severe Tourette's syndrome: a double-blind, randomised crossover trial. Lancet Neurol 2015;14:595-605.

67. Welter ML, Mallet L, Houeto JL, Karachi C, Czernecki V, Cornu $\mathrm{P}$, et al. Internal pallidal and thalamic stimulation in patients with Tourette syndrome. Arch Neurol 2008;65: 952-7.

68. Ackermans L, Duits A, van der Linden C, Tijssen M, Schruers $\mathrm{K}$, Temel Y, et al. Double-blind clinical trial of thalamic stimulation in patients with Tourette syndrome. Brain 2011;134: 832-44.

69. Maciunas RJ, Maddux BN, Riley DE, Whitney CM, Schoenberg MR, Ogrocki PJ, et al. Prospective randomized double-blind trial of bilateral thalamic deep brain stimulation in adults with Tourette syndrome. J Neurosurg 2007; 107:1004-14.

70. Okun MS, Foote KD, Wu SS, Ward HE, Bowers D, Rodriguez RL, et al. A trial of scheduled deep brain stimulation for Tourette syndrome: moving away from continuous deep brain stimulation paradigms. JAMA Neurol 2013;70:85-94.

71. Pringsheim T, Doja A, Gorman D, McKinlay D, Day L, Billinghurst $\mathrm{L}$, et al. Canadian guidelines for the evidence-based treatment of tic disorders: pharmacotherapy. Can J Psychiatry 2012;57:133-43. 